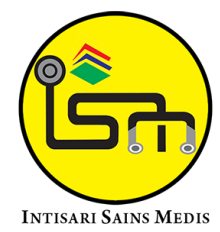

Published by Intisari Sains Medis

\title{
Parametrial hematoma following fetal craniotomy and curettage in intrauterine fetal death: a case report
}

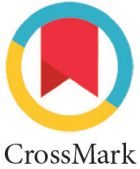

Ida Bagus Yudhistira Anantasurya Vidhisvara ${ }^{1 *}$, Ida Bagus Putu Widiarsa ${ }^{2}$, Margaret Gabriele Helena ${ }^{3}$, I Putu Ivan Cahya Himawan ${ }^{4}$

'Faculty of Medicine, Universitas Tarumanagara, Jakarta, Indonesia;

${ }^{2}$ Department of Obstetrics and Gynecologic, Hermina Kemayoran Hospital, Central Jakarta, Indonesia; ${ }^{3}$ Faculty of Medicine, Widya Mandala Catholic University, Surabaya, Indonesia;

${ }^{4}$ Faculty of Medicine, Universitas Udayana, Bali, Indonesia;

\section{*Corresponding author:}

Ida Bagus Yudhistira Anantasurya Vidhisvara; Faculty of Medicine, Universitas Tarumanagara, Jakarta, Indonesia;

Yudhissurya20@gmail.com

Received: 2021-08-14

Accepted: 2021-10-02

Published: 2021-10-19

\section{ABSTRACT}

Background: Parametrial hematoma is collection of blood located in the parametrial area, which is a type of hematoma that can occur in the pelvic cavity. Postpartum hematoma is a rare but life-threatening complication of childbirth. Common risk factors to developing parametrial hematomas include multiple pregnancies, traumatic deliveries, operative vaginal delivery, prolonged labour, manual removal of placenta, inadequate hemostasis at Caesarean section, preeclampsia, and anticoagulation therapy. We reported a rare case of parametrial hematoma post-craniotomy and curettage of a fetus with intrauterine fetal death (IUFD) in a 28-year-old pregnant woman 24 weeks into her fourth pregnancy.

Case report: A pregnant woman with 24 weeks gestation age came to emergency room with complaints of abdominal pain and bloody discharge without clear fluids 9 hours prior. She was diagnosed with preterm delivery and was given tocolytic. The following day, ultrasound examination was done and fetal heart rate (FHR) was not found, suggesting an intrauterine fetal death (IUFD). Termination was carried out with oxytocin induction but due to maternal

exhaustion, pain, and lack of cooperation, a craniotomy was done in operating room followed by curettage. Twenty-four hours after curettage, patient complained of an acute lower right abdominal pain and ultrasound showed a complex mass in right adnexa measuring 8 $x 8 \mathrm{~cm}$, suggesting a right adnexal hematoma with a differential diagnosis of a right tubo-ovarian abscess. The patient's haemoglobin was found to decrease to $6.0 \mathrm{~g} / \mathrm{dl}$. A laparotomy was performed and a hematoma was found in the right parametrium without active bleeding.

Conclusion: Parametrial hematoma is a rare disease that can occur due to trauma (in labor) or spontaneously due to abnormalities of the uterine arteries that supply blood to the uterus. The patient present in this case report had acute abdominal pain with decreased haemoglobin without signs of bleeding after an operative vaginal birth which may or may not be the cause of the parametrial hematoma due to limitations of examination on the patients. Further observation of similar cases will be required to determine the association between parametrial hematoma and operative vaginal birth.

Keywords: Parametrial hematoma, operative vaginal birth, fetus.

Cite This Article: Vidhisvara, I.B.Y.A., Widiarsa, I.B.P., Helena, M.G., Himawan, I.P.I.C. 2021. Parametrial hematoma following fetal craniotomy and curettage in intrauterine fetal death: a case report. Intisari Sains Medis 12(3): 749751. D0I: $10.15562 /$ ism.v12i3.1108

\section{INTRODUCTION}

Concealed postpartum haemorrhage is a case that requires high suspicion and prompt management to reduce morbidity and mortality. Concealed postpartum haemorrhage can occur intrauterine, intra-abdominal, or within a hematoma. ${ }^{1}$ Postpartum hematoma is a rare but lifethreatening complication of childbirth. Literature reviews have revealed that the incidence of puerperal hematoma varies from 1:309 to 1:1500 deliveries. ${ }^{2}$ Incidents can occur immediately after delivery or during the puerperal period. ${ }^{3}$ Puerperal hematomas are mainly located on the vulva, vagina, broad ligament and rarely but possible happen in the retroperitoneal area. ${ }^{4}$

A pelvic hematoma is a form of postpartum hematoma, which is a collection of blood located in the pelvic peritoneal cavity due to laceration of blood vessels after childbirth or gynaecological procedures. ${ }^{5}$ In the pelvic cavity, hematomas can occur in the ureterovesical space, rectouterine pouch (Douglas' cavity), or in the paravesical, parametrial, paracervical, paravaginal, or pararectal areas. ${ }^{5}$ Retroperitoneal puerperal hematoma which occurs secondary to lacerations of the uterine artery or vessels of the broad ligament is the least common hematoma encountered with an estimated incidence of $1 / 3500$ to $1 / 20,000{ }^{6}$ The most common locations of hematomas are the vulva, vaginal/ paravaginal and retroperitoneal areas resulting from uterine artery injury, and 
occasionally in the hypogastric artery during hysterotomy. ${ }^{5,7}$

Risk factors for injuring the pelvic vasculature and hematoma formation include episiotomy, nulliparity, operative vaginal delivery, breech delivery, delivery of multiples, prolonged second-stage labour, birthweight above $4.000 \mathrm{~g}$, manual removal of placenta, hereditary clotting deficiencies, inadequate hemostasis at Caesarean section, anticoagulant therapy, vulvar varicosities, and pre-eclampsia. ${ }^{7,8}$ A study conducted by Dinulović et al. who assisted 59,068 vaginal deliveries within 7 years, and found 19 occurrences of parametrial hematomas $(0.032 \%)$. In 13 of these 19 cases, Obstructed delivery used assisting instruments, where forceps are used in 6 cases and a vacuum extractor in two instances, while delivery in 5 cases used intravenous Oxytocin injection. Clinically there is a picture of atony or uterine rupture in the majority of cases. In the incidence of parametrial hematoma, a large number of etiologic factors include birth injury, parity, age, predisposing factors, and others. ${ }^{9}$

Other causes of pelvic hematoma include trauma, anticoagulant drugs, and coagulation diseases, ruptured ectopic pregnancy, and ruptured aneurysms in the abdominopelvic vessels. Symptoms usually develop within the first 24 hours after delivery or surgery and vary depending on the location of the hematoma. Symptoms are generally associated with pain and the effects caused by hypovolemia. ${ }^{5}$

\section{CASE REPORT}

A pregnant woman came to emergency room (ER) with complaints of abdominal pain 9 hours prior. This is the patient's fourth pregnancy with a gestational age of 24 weeks. The patient complains a bloody discharge without amniotic fluid. On general examination, Glasgow Coma Scale (CGS) was 15 and vital signs were normal. No abnormalities were found on physical examination. On obstetric examination, the uterine fundal height was $18 \mathrm{~cm}$ and the estimated fetal weight was 775 grams. On Leopold's examination, the fetus was palpated with cephalic presentation. Uterine contraction frequency was $2 \mathrm{x} / 10$ seconds for 30 seconds, with a fetal heart rate (FHR) of 150x/minute.
A vaginal toucher was done and found 2 $\mathrm{cm}$ of opening and negative Litmus test. The patient was diagnosed with $\mathrm{G}_{4} \mathrm{P}_{2} \mathrm{~A}_{1}$ with gestational age of 24 weeks, with premature delivery. The patient was treated with tocolytic until uterine contractions disappear.

Three weeks earlier, the patient had visited ER due to abdominal pain, and was given tocolytic therapy, and was discharged after the condition was under control. At that time, the pregnancy condition was good, the gestational age was 20-21 weeks, but the amniotic fluid was found low with an amniotic fluid index (AFI) of $4.7 \mathrm{~cm}$. The cause was not clear. The patient was given oral therapy with aspirin $80 \mathrm{mg}$ once a day and was advised to return for a follow-up in the next 2 weeks. The patient has an obstetric history of her first and second children born spontaneously at term with birth weights of 2700 grams and 2400 grams, then a spontaneous abortion in her third pregnancy 3 years ago. The patient used an IUD contraceptive which was removed 8 months ago.

The patient was evaluated the next day to find normal vital signs. On obstetric examination, uterine fundal height was at umbilical level, head presentation, weak uterine contraction, and fetal heart rate (FHR) were not found. On examination, vaginal toucher revealed an opening of $3 \mathrm{~cm}$, membrane was not palpable and dry, and the head was palpable with the transverse sagittal suture with Hodge 1 descent. Ultrasound examination was performed with the results: biparietal diameter (BPD): $6.17 \mathrm{~cm} \sim 25 \mathrm{mg}$, head circumference $(\mathrm{HC}): 22.99 \mathrm{~cm} \sim 25 \mathrm{mg}$, abdominal circumference (AC): $20.12 \mathrm{~cm}$ $\sim 24 \mathrm{mg}$, estimated fetal weight (EFW): 795 gr, fetal heartbeat (FHB): (-), Spalding sign (-), AFI: $2.1 \mathrm{~cm}$. Blood examinations showed Hemoglobin $(\mathrm{Hb})$ of $7.5 \mathrm{~g} / \mathrm{dl}$, white blood cells (WBC) of $13.36 \times 109 / 1$, and normal coagulation factors. The patient was diagnosed with $\mathrm{G}_{4} \mathrm{P}_{2} \mathrm{~A}_{1} 24$ weeks of gestation with IUFD, anaemia, and severe oligohydramnios.

Termination of pregnancy was carried out with oxytocin induction. During the observation period, the patient reported feeling pain with visual analogue scale (VAS) around 8-9. The uterine contraction was found inadequate, $2 \mathrm{x} / 10$ seconds for 10-15 seconds. A vaginal toucher was done and found an opening of 9 $\mathrm{cm}, 90 \%$ effacement, and palpable left front crown with a Hodge 2 descent. The patient was found lack cooperation with exhaustion and inadequate pushing. A craniotomy was performed on the fetus in the operating room under intravenous anaesthesia followed by curettage to remove any remnants of conception.

After curettage, ultrasound examination was performed with the results: thin uterine endometrial line, no visible intrauterine hyperechoic shadows, normal right and left ovaries, a complex mass is seen in the right adnexa measuring $8 \times 8 \mathrm{~cm}$. In conclusion, ultrasound showed a right adnexal hematoma with a differential diagnosis of a right tuboovarian abscess. The patient was given antibiotics and analgesics and further observation in the room.

Twenty-four hours post curettage, the patient complained of pain in the lower right abdomen. Vital signs showed blood pressure of $110 / 80 \mathrm{mmHg}$, heart rate of $80 \mathrm{bpm}$, respiratory rate of $18 \mathrm{x} /$ minutes, and oxygen saturation of $99 \%$. Abdominal examination revealed tenderness and rebound tenderness in the lower right area. On vaginal examination, no openings were found on vaginal toucher, there was no clear slinger pain in the portio, a mass of $6 \times 6 \mathrm{~cm}$ was palpable in the right adnexa with pain. In contrast, no abnormalities were found in the left adnexa. Blood examination results showed $\mathrm{Hb}$ of $6.0 \mathrm{~g} / \mathrm{dl}$. The patient was diagnosed with post-curettage acute abdomen and anaemia, with a differential diagnosis of right adnexal haemorrhage and right tubo-ovarian abscess. A laparotomy was planned, considering there were acute abdominal pain and a decrease in haemoglobin.

Laparotomy was performed with transfusion of $300 \mathrm{cc}$ of PRC. During the procedure, the appendix and uterus looked normal, a hematoma was encountered in the right parametrium measuring $10 \times 10$ $\mathrm{cm}$. The peritoneum is opened and 300 cc of blood clots were found. No active bleeding was present. The cavity of the former blood clots is filled with sponges and a drain is installed. One day after the laparotomy, the $\mathrm{Hb}$ level was $9.5 \mathrm{~g} / \mathrm{dl}$ post- 
transfusion of $600 \mathrm{cc}$ PRC, the fluid in the drain was less than $10 \mathrm{cc}$. The drain is then removed and the patient is allowed to go home.

\section{DISCUSSION}

We report the incidence of parametrial hematoma after a fetal craniotomy and curettage at 24 weeks of pregnancy with IUFD. The diagnosis is based on signs and symptoms, physical examination, supporting laboratory tests, and ultrasound. The hematoma was found and the clot was evacuated during laparotomy surgery. No active bleeding was present.

Hematoma can occur in the parametrium but the incidence is relatively small. The parametrium is a fibrous and fatty connective tissue surrounding the uterus, separating the supravaginal portion of the cervix from the bladder. In the parametrium, there are uterine arteries and ovarian ligaments and are loose connective tissue so that when bleeding occurs in the uterine arteries, they form clots and are accumulated in the parametrium. ${ }^{10}$

Looking at the chronology of the patient where 3 weeks before admission to the hospital the patient experienced contractions and oligohydramnios (AFI $4.7 \mathrm{~cm}$ ) without a clear cause, it was suspected that there was a uterine artery blood supply disorder that caused a lack of blood supply to the fetus, decreased urine production and even fetal death. At that time, the results of the ultrasound examination did not show any placental abnormalities. Other abnormalities were suspected, but limitations of the patient's health insurance made it difficult for further exploration, such as the use of Doppler ultrasound. It was possible that at that time there was already a uterine artery leak, maybe even a small parametrial hematoma had occurred, but the ultrasound examination was not clear due to the large uterus with the fetus still in it.

In this case, it is suspected that the parametrial hematoma occurred spontaneously and not due to curettage because there was no uterine laceration after the procedure and at the time of laparotomy the uterus was normal and intact, but delivery and curettage may aggravate the hematoma. This is caused by the shrinking (involution) of the uterus that pulls the uterine artery medially so that the bleeding becomes heavier and within 24 hours after the procedure, acute abdominal symptoms occur. This case differs from broad ligament hematoma, which reported that $50 \%$ of broad ligament hematoma can be recognized immediately after delivery because these acute hematomas are generally caused by trauma during delivery. ${ }^{11}$

\section{CONCLUSION}

Parametrial hematoma can occur due to trauma (in labor) or spontaneously due to abnormalities of the uterine arteries that supply blood to the uterus. Although rare, postpartum hematomas should be considered in puerperal patients presenting with lower abdominal pain following normal vaginal delivery. A hematoma should be considered if there is a significant decrease in hemoglobin $\mathrm{Hb})$ while there are no signs of bleeding. If oligohydramnios develops without an apparent cause, the possibility of uterine artery bleeding should be considered. Rapid clinical diagnosis and appropriate management are essential to prevent severe hematoma and reduce patient morbidity. Ultrasonography is an important examination procedure to reach a precise diagnosis.

\section{CONFLICT OF INTEREST}

All author declares that there is no conflict of interest regarding publication of the case report.

\section{FUNDING}

This report doesn't receive any specific grant from government or any private sector.

\section{AUTHOR CONTRIBUTION}

All authors had contributed to the manuscript writing and agreed for the final version of the published case report.

\section{ETHICAL ASPECT}

The patient had received signed written informed consent regarding publication of their medical data in medical journal as a case report.

\section{REFERENCES}

1. Deng L, Naidu S. Ultrasound of a late onset postpartum broad ligament haematoma. Sonography. 2020;7(2):83-7.

2. Acreman ML, Sainani M. Retzius space haematoma as a rare cause of concealed retroperitoneal postpartum haemorrhage following spontaneous vaginal delivery. BMJ Case Rep. 2018;2018:1-3.

3. Rafi J, Khalil H. Maternal morbidity and mortality associated with retroperitoneal haematomas in pregnancy. JRSM Open. 2018;9(1):205427041774605.

4. Park M, Han S-S. A case of secondary postpartum haemorrhage with shock followed by rupture of progressive retroperitoneal hematoma through left upper vaginal wall. Korean J Obstet. 2011;54(6):314.

5. Mirza FG, Gaddipati S. Obstetric Emergencies. Semin Perinatol. 2009;33(2):97-103.

6. Alturki F, Ponette V, Boucher LM. Spontaneous Retroperitoneal Hematomas Following Uncomplicated Vaginal Deliveries: A Case Report and Literature Review. J Obstet Gynaecol Canada. 2018;40(6):712-5.

7. Rafi J, Muppala H. Retroperitoneal haematomas in obstetrics: literature review. Arch Gynecol Obstet. 2009;281(3):435-41. Available from: http://dx.doi.org/10.1007/s00404-009-1282-y

8. Alturki F, Ponette V, Boucher LM. Spontaneous Retroperitoneal Hematomas Following Uncomplicated Vaginal Deliveries: A Case Report and Literature Review. J Obstet Gynaecol Canada. 2018;40(6):712-5. Available from: http://dx.doi.org/10.1163/2210-7975_ hrd-1034-0115

9. Gama $\mathrm{CH}$, Fenichel GM. Epidural hematoma of the newborn due to birth trauma. Pediatr Neurol. 1985;1(1):52-3. Available from: http:// dx.doi.org/10.1016/0887-8994(85)90010-4

10. Bobak IM JM. Maternity And Gynecologic Care. AJN, Am J Nurs. 1985;85(12):1345. Available from: http://dx.doi.org/10.1097/00000446198512000-00028

11. Korde-Nayak V, Biniwale P. Broad Ligament Haematoma. Labour Room Emergencies. Springer Singapore; 2019. p. 395-402. Available from: http://dx.doi.org/10.1007/978-981-104953-8_41

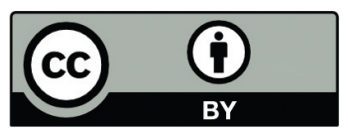

This work is licensed under a Creative Commons Attribution 